\title{
Effect of surface morphology on atmospheric corrosion behaviour of Fe-based metallic glass, $\mathrm{Fe}_{67} \mathrm{Co}_{18} \mathrm{Si}_{14} \mathrm{~B}_{1}$
}

\author{
B VISHWANADH*, R BALASUBRAMANIAM ${ }^{\dagger}$, D SRIVASTAVA and G K DEY \\ Materials Science Division, Bhabha Atomic Research Centre, Mumbai 400 085, India \\ ${ }^{\dagger}$ Department of Materials and Metallurgical Engineering, Indian Institute of Technology, Kanpur 208 016, India
}

MS received 25 October 2007; revised 19 March 2008

\begin{abstract}
The nature of atmospheric corrosion behaviour of an as-cast metallic glass, $\mathrm{Fe}_{67} \mathrm{Co}_{18} \mathrm{Si}_{1} \mathrm{~B}_{14}$ ribbon, was evaluated. The wheel side surface of the ribbon was more corroded than the air side surface, due to the higher density of air pockets present. The phases present in atmospheric rust were analysed by X-ray diffraction (XRD) and Fourier transform infrared spectroscopy (FTIR) to be goethite, lepidocrocite, magnetite, cobalt oxide and cobalt hydroxide phases. Goethite and lepidocrocite were in amorphous form. The nature of rusting was understood by scanning electron microscopy (SEM). Nucleation of rust started at preferred locations on the surface and grew along the surface in certain directions.
\end{abstract}

Keywords. Atmospheric corrosion; metallic glasses; amorphous structure.

\section{Introduction}

Metallic glasses are non-crystalline metallic solids. Alloys with low glass-forming ability are obtained in the noncrystalline solid condition by rapid solidification $\left(>10^{4} \mathrm{~K} / \mathrm{s}\right)$ of the melt. This is the case with iron-based metallic glasses, which is the material of concern in the present study. It may be relevant to note here that metallic glasses are also produced in rod form even at low cooling rates and these are called bulk metallic glasses. In case of ironbased metallic glasses, they should have atleast one small dimension to achieve very high cooling rates. Therefore, these metallic glasses are produced in the form of strips and sheets. These shapes possess high surface area to volume ratios. Environmental stability and/or corrosion resistance in service is extremely important because even a normal corrosion rate may lead to loss of integrity and failure. Moreover, in thin sections, localized attack (pitting) leads to rapid local perforation.

Amorphous materials generally possess better corrosion resistance as compared to crystalline materials because of the absence of defects such as grain boundaries, vacancies and dislocations (Dutta and Dey 2003). During synthesis of metallic glass ribbons, the bottom surface of the ribbon is in contact with the wheel, whereas the top side surface is in contact with air. A comparatively slower cooling rate of the air side surface than the other side generally induces partial crystallinity in the air side. From corrosion point of view, the presence of microcry-

*Author for correspondence (visubathula@yahoo.co.in) stalline phase in the amorphous matrix has been reported to be detrimental (Zhang et al 1991, 1992; Dutta et al 1995). The wheel side surface is also susceptible to corrosion because of the presence of air pockets. Air pockets mostly exist in the wheel side surface of the ribbon. These originate from entrapment of air during the production of alloy ribbons by rapid solidification. These air pockets are usually randomly distributed in the wheel side surface with varying sizes (Dutta et al 1995). These deficiencies like partial crystallinity (Dutta et al 1995; Savalia et al 1996), air pockets (Gravano et al 1992) and local compositional inhomogeneities (Devine and Wells 1976) act as nucleating sites for corrosion in metallic glasses.

The corrosion behaviour of several metallic glasses in aqueous solutions has been well studied. In case of corrosion of rapidly solidified $\mathrm{Ti}_{47} \mathrm{Cu}_{53}$ and $\mathrm{Ti}_{50} \mathrm{Cu}_{50}$ alloy in acidic chloride environment at room temperature (Dutta et al 2001), the air-formed oxide films and defects introduced in the alloy ribbons during their production influence the corrosion resistance of the alloy ribbon. According to Dey et al (1989), among the three factors, viz., partial crystallinity, air pockets and compositional difference induced in rapidly solidified $\mathrm{Zr}_{76} \mathrm{Ni}_{16} \mathrm{Fe}_{8}$ (Dey et al 1989) alloy ribbon, partial crystallinity was the most harmful to its corrosion resistance in chloride environments. The adverse effect of quenched-in defects on the corrosion resistance of $\mathrm{Fe}_{34} \mathrm{Ni}_{36} \mathrm{Cr}_{10} \mathrm{P}_{14} \mathrm{~B}_{6}$ amorphous alloy has been reported by some investigators (Gravano et al 1992). The inferior corrosion resistance of the wheel side surface has been attributed to higher concentration of quenchedin defects due to higher cooling rate (Gravano et al 1992). 
The effect of compositional difference on the electrochemical behaviour of the alloy ribbon has been investigated by some researchers (Devine and Wells 1976). The observed difference in electrochemical behaviour of the alloy ribbon across its thickness is attributed to the compositional differences. Several studies have been carried out on the corrosion aspects of various iron-based amorphous alloys. Karve and Kulkarni (1985) studied the effect of cation associated with chloride and sulphate ions on the corrosion of metallic glass, $\mathrm{Fe}_{67} \mathrm{Co}_{18} \mathrm{Si}_{1} \mathrm{~B}_{14}(2605 \mathrm{CO})$. The weight loss in sulphate media $\left(\mathrm{H}_{2} \mathrm{SO}_{4}, \mathrm{Li}_{2} \mathrm{SO}_{4}\right.$, $\mathrm{Na}_{2} \mathrm{SO}_{4}$ and $\mathrm{K}_{2} \mathrm{SO}_{4}$ ) was less than that in the corresponding chloride solutions. The weight loss decreased with increase in the atomic number of the cation in solution, for both chlorides and sulphates. Sharma et al (1990) compared corrosion behaviour of $\mathrm{Fe}_{67} \mathrm{Co}_{18} \mathrm{Si}_{1} \mathrm{~B}_{14}$ (2605CO), $\mathrm{Fe}_{81} \mathrm{Co}_{13.5} \mathrm{Si}_{3.5} \mathrm{C}_{2}$ (2605SC) with $\mathrm{Fe}_{80} \mathrm{~B}_{20}$ in $0.5 \mathrm{M} \mathrm{K}_{2} \mathrm{SO}_{4}$ solution. Neither of the alloys exhibited passivity during anodic polarization (Singh et al 1986). The two amorphous alloys (2605CO and 2605SC) were more resistant to corrosion in potassium sulphate solution as compared to the binary $\mathrm{Fe}_{80} \mathrm{~B}_{20}$ glass. Enrichment of the constituent metalloid species (B and $\mathrm{Si}$ ) in the surface film contributes to this enhanced corrosion resistance, in the case of the $2605 \mathrm{CO}$ glass. The relative effectiveness of metalloids in metal-metalloid glasses in enhancing the corrosion resistance is believed to be in the decreasing order $\mathrm{P}, \mathrm{C}, \mathrm{Si}$ and B (Hashimoto et al 1979).

The corrosion studies of all the metallic glasses have been restricted to aqueous solution corrosion. Therefore, in the present work, effect of surface morphology on the atmospheric corrosion behaviour of an iron based metallic glass, $\mathrm{Fe}_{67} \mathrm{Co}_{18} \mathrm{Si}_{1} \mathrm{~B}_{14}$, has been investigated. This alloy is also known by the commercial name, Metglas $2605 \mathrm{CO}$, and is well known for transformer applications. The nature of surface phases has been understood by scanning electron microscopy (SEM), Fourier transform infra-red spectroscopy (FTIR) and X-ray diffraction (XRD).

\section{Experimental}

In order to produce the amorphous metallic glass ribbon, $100 \mathrm{~g}$ of $\mathrm{Fe}_{67} \mathrm{Co}_{18} \mathrm{Si}_{1} \mathrm{~B}_{14}$ alloy was prepared by mixing pure material charge ( $\mathrm{Fe}(75.1 \mathrm{~g})$, Co (21.29 g), B (3.04 g) and $\mathrm{Si}(0.56 \mathrm{~g}))$. This alloy was melted in a vacuum arc melting furnace and subsequently ribbons were produced by the melt spinning process. The wheel speed was maintained at $55 \mathrm{~m} / \mathrm{s}$. The ribbons were $20-30 \mu \mathrm{m}$ in thickness and $1.5-2 \mathrm{~mm}$ in width. The local compositions of the ribbons were obtained by compositional analysis in a Cameca SX 100 electron probe microanalyser operated at $15 \mathrm{kV}$. A Philips PW 1830 X-ray diffractometer and a TEM (JEOL2000FX) operated at $160 \mathrm{kV}$ was used to confirm the amorphous phase present in the as-cast metallic glass. The indoor atmospheric corrosion of the samples was studied by exposing the samples in room atmospheric condition for 4 months. The size of the sample was $3 \mathrm{~cm}$ in length, $2.4 \mathrm{~mm}$ in width and $25 \mu \mathrm{m}$ in thickness. Before exposing the samples in indoor atmosphere, they were washed thoroughly with acetone and distilled water and dried in hot air. The rust along with substrate was characterized by scanning electron microscopy (FEI QUANTA 200) and X-ray diffractometer. The phases present in the rust were identified by analysing XRD pattern and the Fourier transform infrared (FTIR) spectra. The FTIR spectra from the rust samples were recorded using a Brucker model FTIR spectrometer by the $\mathrm{KBr}$ pellet technique.

\section{Results and discussion}

\subsection{Characterization of as-cast metallic glasses}

In order to understand the difference in as-cast structure of ribbons, X-ray diffraction (XRD) patterns were obtained from both sides (wheel and air side) of melt spun ribbons. XRD patterns showed two humps, without any distinct peaks that are characteristic of crystalline phases (figure 1). The angular spread of the humps was in the range of $15-20^{\circ}$. For crystalline peaks, angular spread should be within $2-3^{\circ}$ (Du and Ramanujan 2004). Therefore, the XRD patterns indicated that the as-cast metallic glass was amorphous on both the sides. However, the XRD technique cannot detect crystalline phases if their volume fraction is less than $\mathbf{5 \%}$. Therefore, there may be a possibility of presence of up to $5 \%$ crystalline volume fraction in the as-cast metallic glasses. In order to confirm this, TEM analysis was performed on the as-cast melt spun ribbons. Figure 2 shows the bright field and selected area electron diffraction (SAED) pattern of as-cast melt

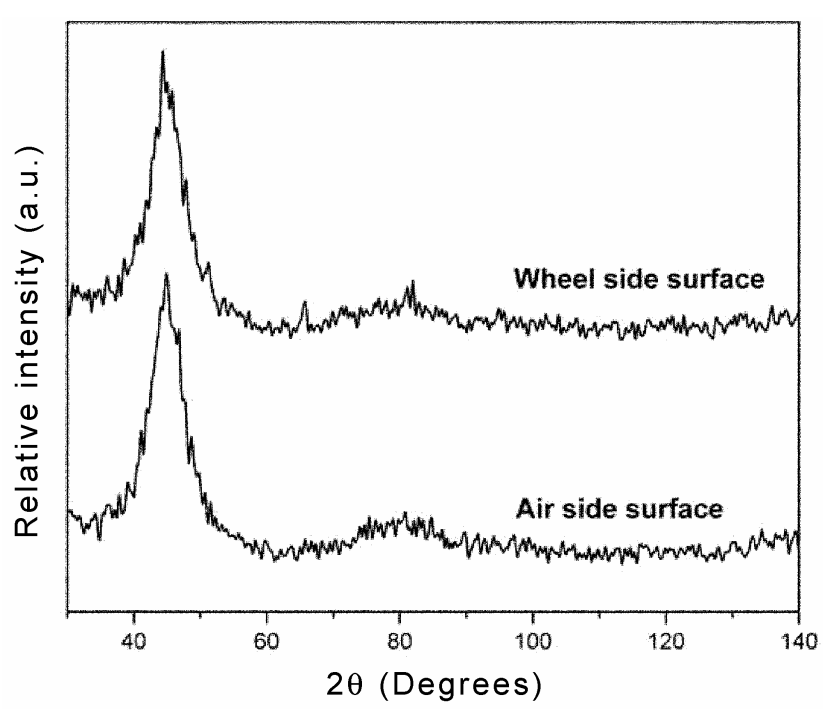

Figure 1. XRD patterns of as-cast $\mathrm{Fe}_{67} \mathrm{Co}_{18} \mathrm{Si}_{1} \mathrm{~B}_{14}$ melt-spun ribbons. 
spun ribbons. The bright field image of the as-cast $\mathrm{Fe}_{67} \mathrm{Co}_{18} \mathrm{Si}_{1} \mathrm{~B}_{14}$ melt-spun ribbons did not show any contrast, because of the absence of grain boundaries and second phase particles. The SAED pattern exhibited a diffuse halo due to amorphous structure. Based on these XRD and TEM observations, it was confirmed that as-cast meltspun ribbons were fully amorphous.

The surface topography of as-cast melt spun ribbons was analysed by scanning electron microscopy (SEM). This analysis was carried out on both the surfaces (air and wheel side) of ribbon. Figure 3 shows the SEM images of wheel and air side surfaces. The wheel side surface showed more air pockets that appear as depressions than the air side surface.

During melt spinning, in the case of air side surface, the air ejects to the outside. However, in the case of wheel side surface, air entraps between wheel and ribbon surface due to high speed of the wheel. This results in the presence of air pockets on the wheel side surface. The presence of these air pockets on the wheel side surface makes it appear as duller compared to the air side surface. Hence, the wheel side surface shows more air pockets than the air side surface.

Local compositions were also evaluated using EPMA. Typical EPMA results from two locations on the wheel side surface were (in atomic percent) Fe- $67 \cdot 45 \%$, Co- $19 \cdot 45 \%$, B-13.30\% and $\mathrm{Si}-1.05 \%$ (region one which was a matrix

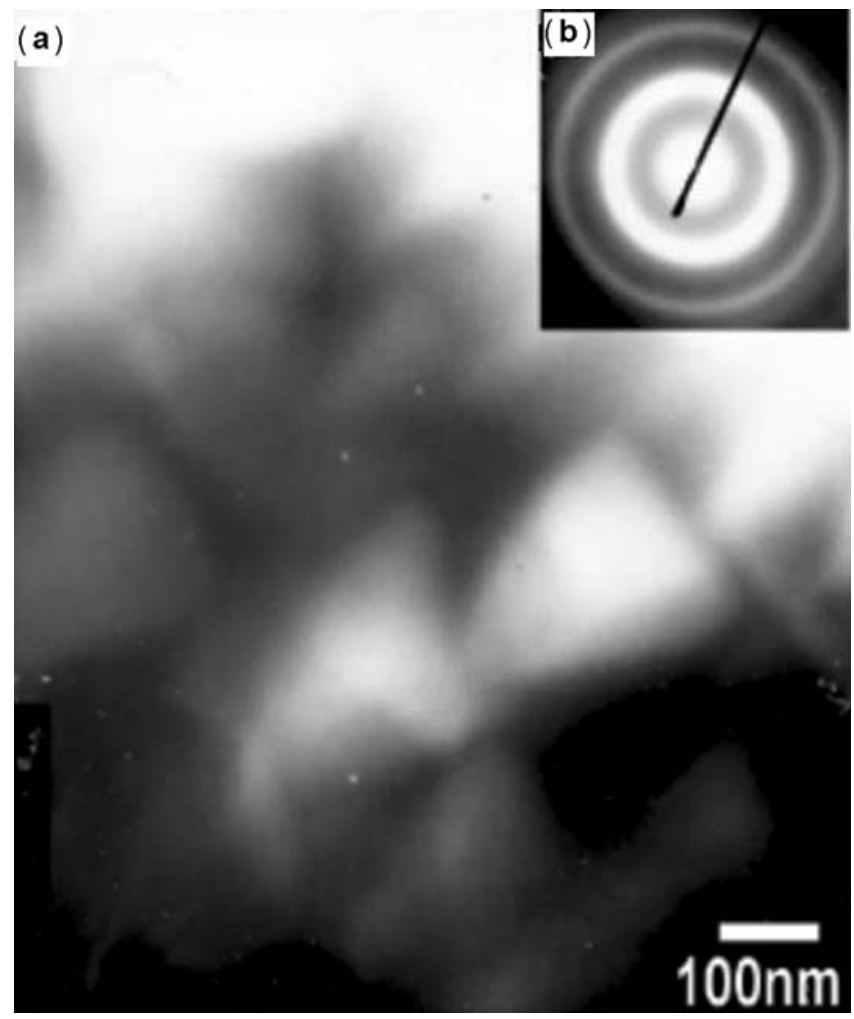

Figure 2. (a) Bright field image and (b) selected area diffraction pattern from as-cast melt spun ribbon. location) and $\mathrm{Fe}-66 \cdot 85 \%$, Co- $19 \cdot 40 \%$, B- $12 \cdot 60 \%$ and Si$1 \cdot 15 \%$ (region two which was typically an air pocket location). There was no major variation in chemical composition at air pockets and matrix regions. This indicates that the composition of the metallic glass was homogeneous.

\subsection{Analysis of corroded metallic glasses}

Both sides of the corroded sample were characterized by SEM. The SEM topologies of air and wheel side surfaces of the exposed sample are shown in figures 4(a) and (b), respectively. The wheel side surface was corroded more than the air side surface, as can be noted from the topological features. Air pockets could be the main deficiencies responsible for corrosion, as these act as preferential sites for corrosion (see figure 4(b)). Air pockets possess high curved surface area, which leads to enhanced electron transfer (oxidation reaction) at localized regions, resulting in higher corrosion (Dutta and Dey 2003).

The present study specifically addresses atmospheric corrosion and the behaviour of metallic glasses for the first time. The effect of air and wheel side surfaces is known for aqueous corrosion condition. For example, Dutta et al (2003) observed similar effect of wheel and air side surface on aqueous corrosion behaviour of $\mathrm{Ti}-\mathrm{Cu}$ metallic glass in $0.5 \mathrm{M} \mathrm{H}_{2} \mathrm{SO}_{4}+0.5 \mathrm{M} \mathrm{NaCl}$ and $0.01 \mathrm{~N}$ $\mathrm{HCl}$ solutions. In both the solutions, the alloy exhibited
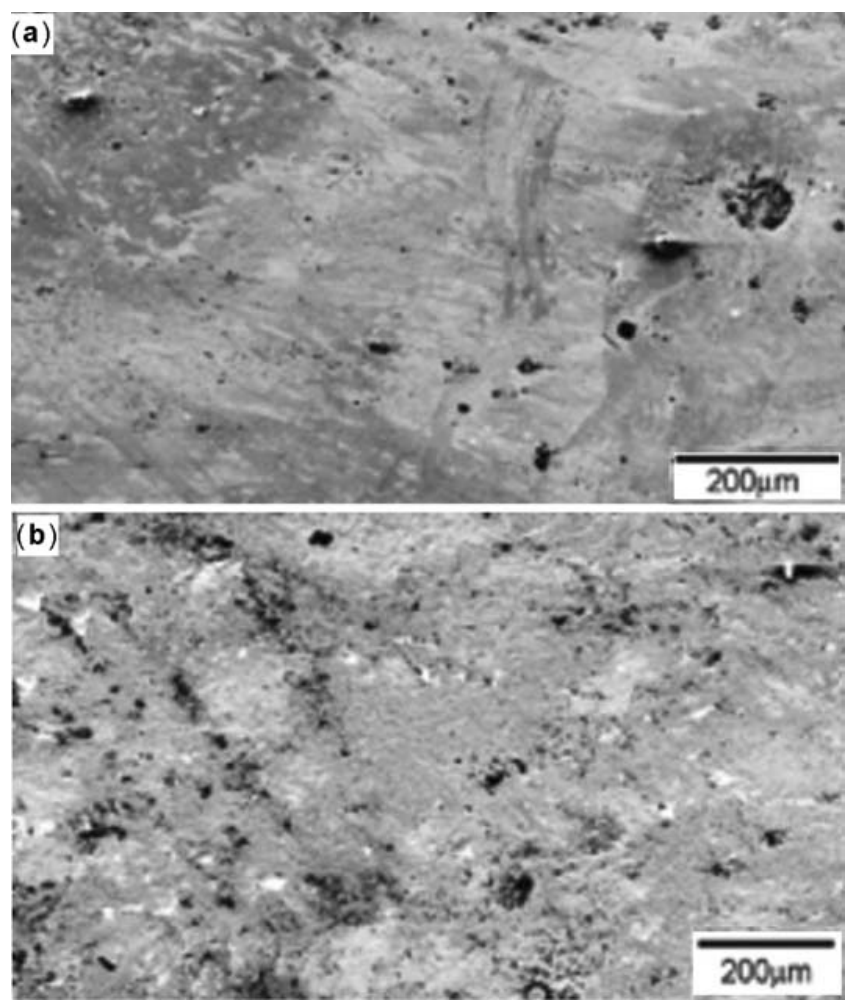

Figure 3. SEM microstructures of (a) air (bright) side surface and (b) wheel (dull) side surface. 
passivity followed by pitting corrosion. The wheel side surface showed lower pitting potential and higher anodic current density. These observations were attributed to the presence of more air pockets on wheel side than the air side surface. Moreover, the high concentration of air pockets favoured easier passive film breakdown by acting as pitting initiation sites (Dutta and Dey 2003).

Figure 5 shows some interesting features regarding the nucleation and growth of the atmospheric rust layer. Nucleation of rust starts at some preferred locations, which are regions of air pockets (figure 5a) and grows along surface in certain directions (figure $5 b$ ).

The XRD pattern obtained from the rusted wheel side surface (figure 6) showed amorphous structure similar to as-cast XRD pattern (see figure 1). Some peaks due to
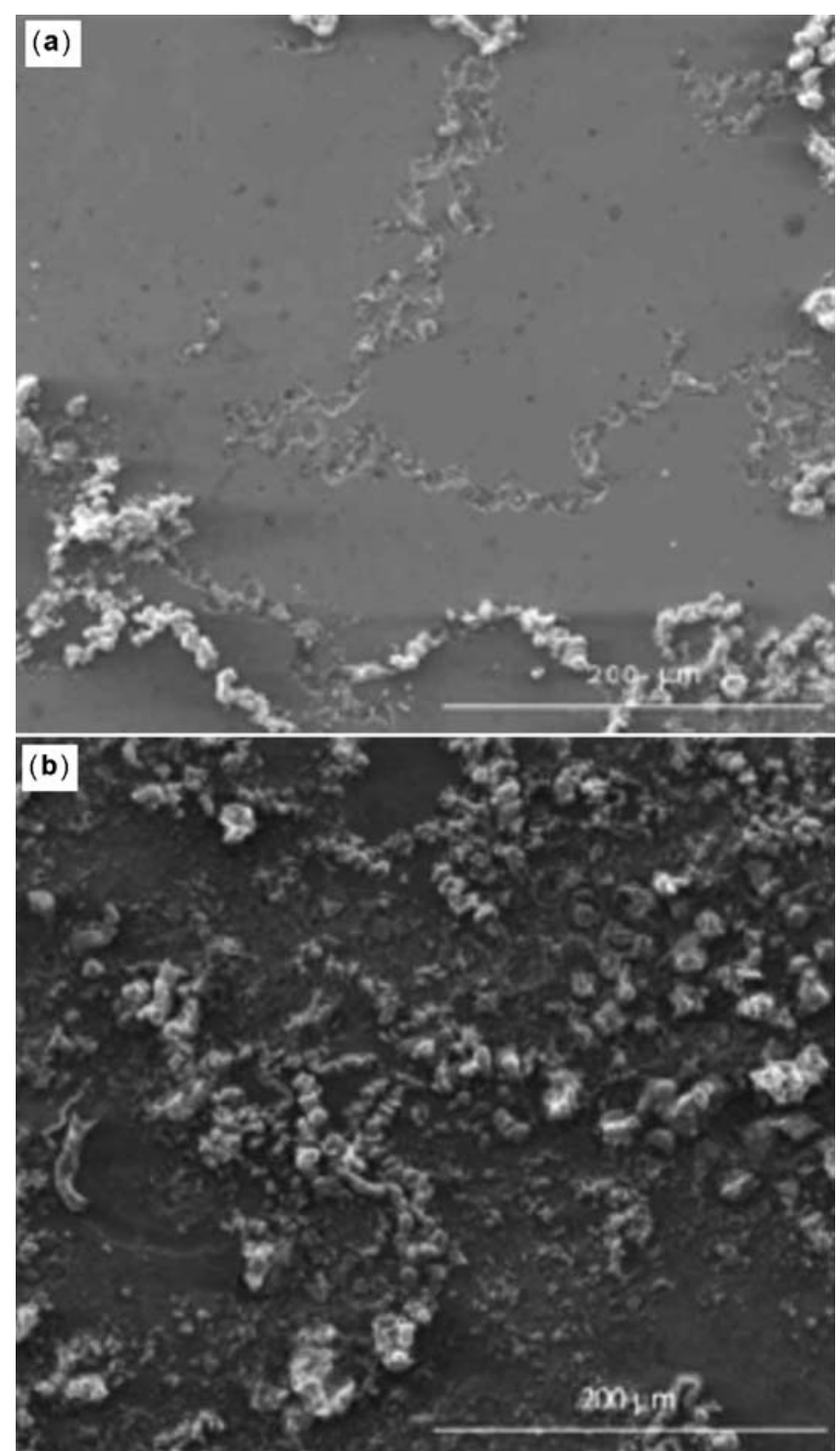

Figure 4. SEM images of $\mathrm{Fe}_{67} \mathrm{Co}_{18} \mathrm{Si}_{1} \mathrm{~B}_{14}$ metallic glass exposed to atmosphere for 4 months showing (a) air side and (b) wheel side surface. corrosion product were observed. These peaks were identified as cobalt hydroxide $\left(\mathrm{Co}(\mathrm{OH})_{2}\right)$ and magnetite $\left(\mathrm{Fe}_{3} \mathrm{O}_{4}\right)$ phases. The intensity of these peaks was low. It could be because of the low volume fraction of rust. The XRD technique cannot detect amorphous phases present in the rust. In this regard, infrared (IR) spectroscopy is useful to identify amorphous (and crystalline) phases because the identification is based on known vibrations between constituent atoms/ions. Therefore, IR spectroscopy will reveal all phases irrespective of their crystallinity.

Figure 7 shows the IR spectra for the rust of wheel side surface. The presence of magnetite $\left(\mathrm{Fe}_{3} \mathrm{O}_{4}\right)$, goethite $(\alpha$ $\mathrm{FeOOH})$, lepidocrocite $(\gamma-\mathrm{FeOOH})$ and cobalt hydroxide $\left(\mathrm{Co}(\mathrm{OH})_{2} \cdot \mathrm{H}_{2} \mathrm{O}\right)$ was confirmed by the appearance of peaks at $515 \mathrm{~cm}^{-1}, 860 \mathrm{~cm}^{-1}, 987 \mathrm{~cm}^{-1}$ and $1641 \mathrm{~cm}^{-1}$, respectively

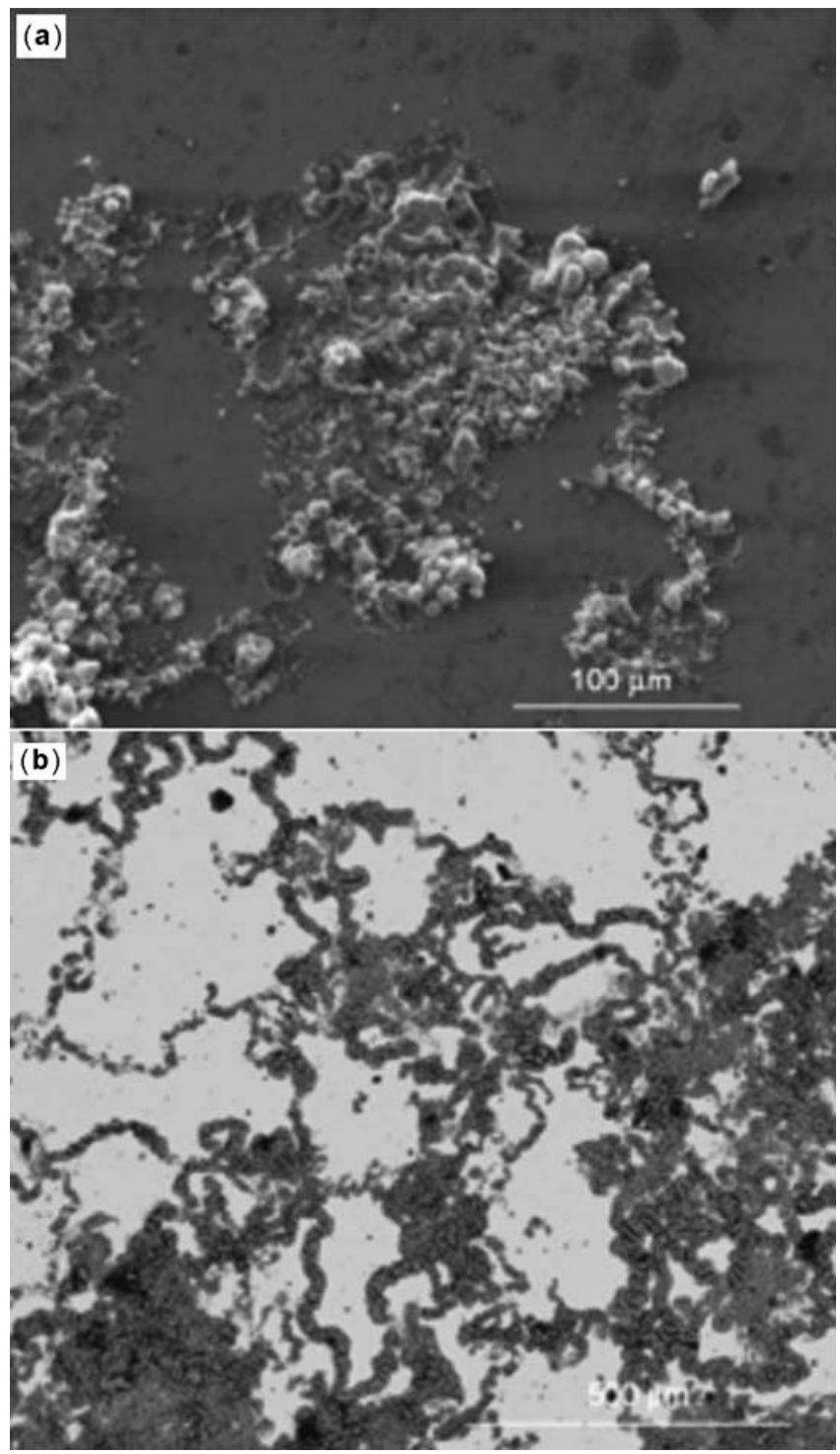

Figure 5. SEM images of wheel side surface at different locations of $\mathrm{Fe}_{67} \mathrm{Co}_{18} \mathrm{Si}_{1} \mathrm{~B}_{14}$ metallic glass exposed to atmosphere for 4 months showing (a) regions of air pockets and (b) growth of rust along certain directions. 
(Misawa et al 1971, 1974; Pejova et al 2001; Cornell and Schwertmann 2003). The broad hump at 3702-1783 $\mathrm{cm}^{-1}$ was attributed to adsorbed water (Venkat narayan et al 2006).

The published wave numbers for the iron and cobalt rusts (Misawa et al 1971, 1974; Pejova et al 2001; Cornell and Schwertmann 2003) are $580 \mathrm{~cm}^{-1}\left(\mathrm{Fe}_{3} \mathrm{O}_{4}\right), 890 \mathrm{~cm}^{-1}$ $(\alpha-\mathrm{FeOOH}), 1020 \mathrm{~cm}^{-1}(\gamma-\mathrm{FeOOH}), 1385$ and $1637 \mathrm{~cm}^{-1}$ $\left(\mathrm{Co}(\mathrm{OH})_{2} \cdot x \mathrm{H}_{2} \mathrm{O}\right)$. The observed peaks were slightly shifted compared to standard literature data. This can be explained by the presence of other ions in the rust due to alloying elements in the metallic glass.

SEM micrographs from rusted region on the wheel side showed spherical and faceted morphology of rust constituents (figure 8). The morphology of rust matches with the morphology of goethite, lepidocrocite, magnetite and

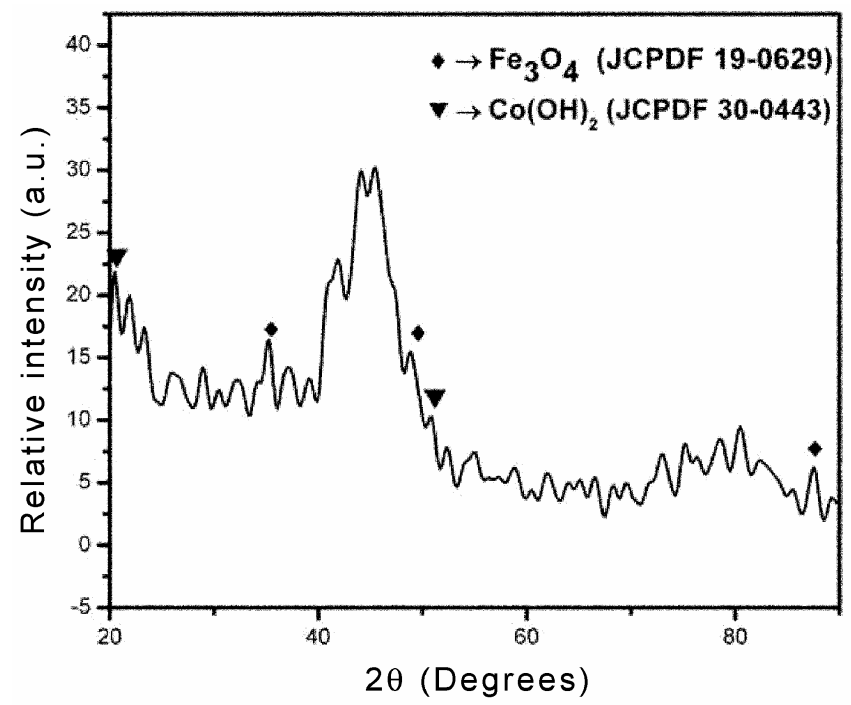

Figure 6. XRD pattern of wheel side surface of $\mathrm{Fe}_{67} \mathrm{Co}_{18} \mathrm{Si}_{1} \mathrm{~B}_{14}$ metallic glass after exposure to atmosphere for 4 months.

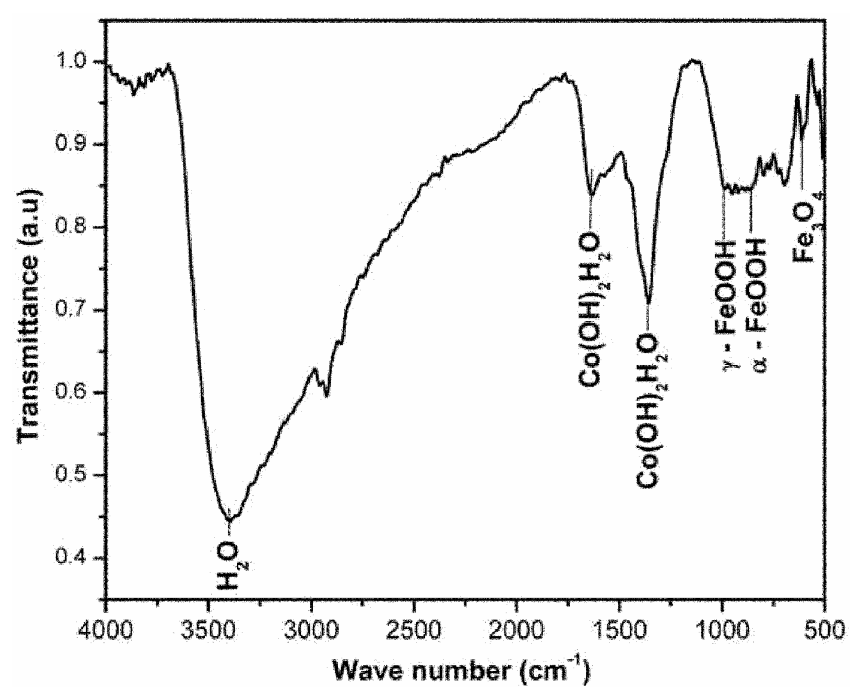

Figure 7. FTIR spectrum from rust obtained from wheel side metallic glass after exposure to atmosphere for 4 months. cobalt hydroxide phases (Cornell and Schwertmann 2003; Liu et al 2005). The magnetite phase possesses spherical, goethite and lepidocrocite faceted type and cobalt hydroxide possesses hexagonal plate like morphology.

From these studies, it can be concluded that the rust was composed of iron and cobalt oxide, hydroxide phases. Sharma et al (1990) determined the phases present in the corrosion film on $2605 \mathrm{CO}$ alloy formed in potassium sulphate solution using X-ray photoelectron spectroscopy. The corrosion film consisted of a mixture of $\mathrm{FeOOH}$ and $\mathrm{Co}(\mathrm{OH})_{2}$ phases (Sharma et al 1990). In the present case, rust formed in atmospheric environment consisted of similar kind of phases.

Figure 9 shows high magnification SEM images of the directional morphology of rust shown in figure 5(b). At some locations, rust was peeled off during handling. The
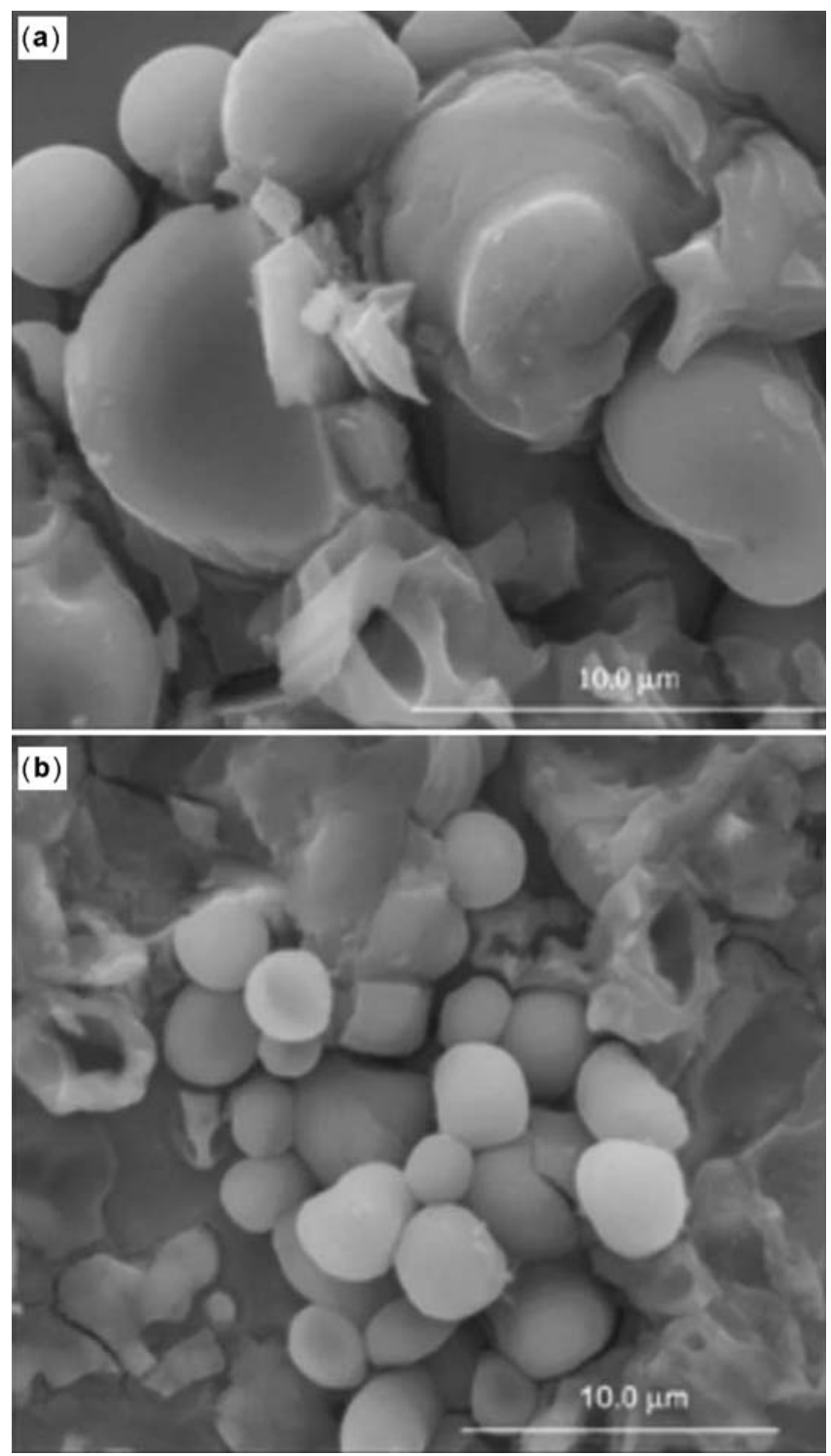

Figure 8. High magnification SEM images of wheel side surface at different locations of $\mathrm{Fe}_{67} \mathrm{Co}_{18} \mathrm{Si}_{1} \mathrm{~B}_{14}$ metallic glass exposed to atmosphere for 4 months. 

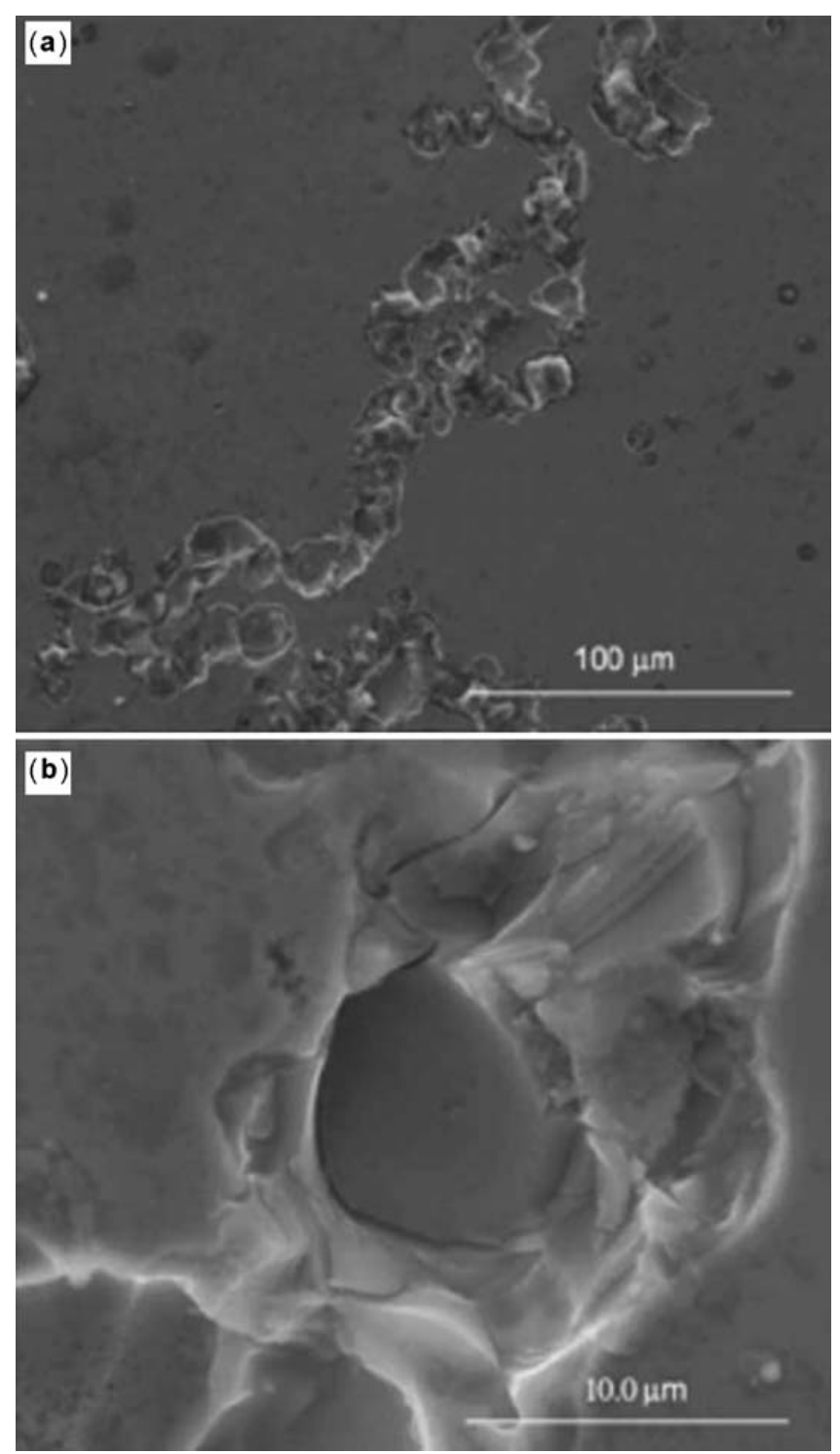

Figure 9. SEM images of wheel side surface showing (a) directional nature of attack and (b) rusted region from where the rust had peeled off.

regions that appeared pitted (figure 9(a)) are the locations from where the rust had spalled off. Higher magnification views of the pitted region indicate that the atmospheric rust nucleated with some preferred orientation (see figure 9(b)). From these observations, it can be hypothesized that nucleation and growth of rust followed local defect structure. The localized corrosion may be due to the higher rate of corrosion reaction at these locations, which probably results from the nature of moisture condensation at these locations.

\section{Conclusions}

The following conclusions have been drawn from the present work.
(I) Characterization of as-cast melt-spun ribbon, $\mathrm{Fe}_{67} \mathrm{Co}_{18}$ $\mathrm{Si}_{1} \mathrm{~b}_{14}$, which was produced by melt spinning technique, revealed that the as-cast structure of the metallic glass was fully amorphous.

(II) The corrosion at the wheel side surface of the as-cast melt spun ribbon was higher than the air side surface, which has been related to surface morphology (i.e. air pockets) due to processing of the ribbons.

(III) The atmospheric rust nucleated with some preferred orientation to the substrate and the growth of rust was of directional nature, resembling the growth morphology in filiform corrosion.

(IV) The atmospheric rust was composed of goethite, lepidocrocite, magnetite and cobalt hydroxide phases. Goethite and lepidocrocite were mainly in the amorphous state.

\section{References}

Cornell R M and Schwertmann U 2003 The iron oxides (structure, properties, occurrences and uses) (Weinheim: Wiley VCH Verlag GmbH \& Co. ), pp 141-146 and 59-64

Devine T M and Wells L 1976 Scr. Metall. Mater. 10309

Dey G K, Savalia R T, Sharma S K and Kulkarni S K 1989 Corros. Sci. 29823

Du S W and Ramanujan R V 2004 Mater. Sci. Eng. 3751040

Dutta R S and Dey G K 2003 Bull. Mater. Sci. 26477

Dutta R S, Savalia R T and Dey G K 1995 Scr. Metall. Mater. 32207

Dutta R S, Savalia R T and Dey G K 2001 Br. Corros. J. 36 221

Gravano S M, Torchio S, Mazza F, Angelini E and Baricco M 1992 Corros. Sci. 331227

Hashimoto K, Asami K, Naka M and Masumoto M 1979 Corros. Sci. 19857

Karve P P and Kulkarni S K 1985 Corros. Sci. 251091

Liu Z, Ma R, Osada M, Takada K and Sasaki T $2005 \mathrm{~J}$. Am. Chem. Soc. 12713869

Misawa T, Kyuno T, Suetaka W and Shimodaira S 1971 Corros. Sci. 1135

Misawa T, Asami K, Hashimoto K and Shimodaira S 1974 Corros. Sci. 14279

Pejova B, Isahi A, Najdoski M and Grozdanov I 2001 Mater. Res. Bull. 36161

Savalia R T, Tewari R, Dey G K and Banerjee S 1996 Acta Mater. 4457

Sharma S K, Mukhopadhyay P, Chauhan P K and Kulkarni S K 1990 Corros. Sci. 30313

Singh I B, Chaudhary R S and Nambodhiri T K G 1986 Mater. Sci. Eng. 83126

Venkat narayan R, Vinod K and Dhathathreyan A $2006 \mathrm{~J}$. Chem. Sci. 118179

Zhang B P, Habazaki H, Kawashima A, Asami K, Hiraga K and Hashimoto K 1991 Corros. Sci. 32433

Zhang B P, Habazaki H, Kawashima A, Asami K and Hashimoto K 1992 Corros. Sci. 33103 